\title{
B Cells Compartment in Centenarian Offspring and Old People
}

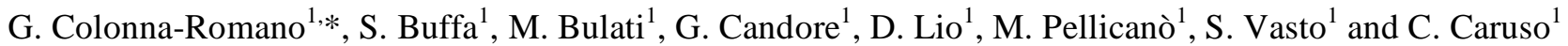

${ }^{1}$ Immunosenescence Unit, Department of Pathobiology and Biomedical Methodologies, University of Palermo, Italy

\begin{abstract}
Immunosenescence is considered a major contributory factor to the increased frequency of morbidity and mortality among elderly. On the other hand centenarians are considered the best example of successful ageing. To gain insight into mechanisms of immunosenescence and its clinical relevance, a possible model is represented by centenarians and/or their offspring. Nowadays centenarians are not more a curiosity, but in Europe are 1/8000 inhabitants and it has been demonstrated that the centenarian offspring, who are typically in their $70 \mathrm{~s}$ and $80 \mathrm{~s}$, have a survival advantage when compared with age-matched controls whose parents died at an average life expectancy. Then again, studies on immunosenescence focus mainly on $\mathrm{T}$ cell impairment, although B cells are also affected. So, in the present preliminary report, we have studied B cell compartment in two classes of individuals, old people and centenarian offspring. B cell compartment was analysed using anti-IgD and $\mathrm{CD} 27$ antibodies which characterize naïve $\mathrm{B}$ cells (IgD $\left.{ }^{+} \mathrm{CD} 27^{-}\right)$, memory unswitched $\mathrm{B}$ cells $\left(\operatorname{IgD} \mathrm{CD}^{+} 27^{+}\right)$, memory switched $\mathrm{B}$ cells $\left(\operatorname{IgD} \mathrm{CD}^{-} 7^{+}\right)$and double negative $\mathrm{B}$ cells $(\mathrm{DN})\left(\operatorname{IgD} \mathrm{CD}^{-} 7^{-}\right)$, i.e. exhausted memory cells. As expected, in both cohorts we observed a decreased B cell count. However, in centenarian offspring, naïve B cells are more abundant whereas exhausted memory cells (DN B cells, IgD $\mathrm{ID}^{-} 27^{\circ}$ ) do not show the increase that we have previously demonstrated in healthy elderly donors. These data are similar to that found in previously experiments on young subjects. So, our preliminary results show that centenarian offspring do not have the typical trend of memory/naive B cell subsets observed in elderly people and this is in agreement with the higher levels of IgM in the serum of centenarian offspring in comparison with data obtained in age-matched controls. This reservoir of naive B cell might be one of the causes that make centenarian offspring able to keep fighting off new infections, hence prolonging their life. So, B cell subset changes could represent a hallmark of successful or unsuccessful ageing and could be used as a biomarker of human life span, potentially useful for the evaluation of anti-ageing treatment.
\end{abstract}

Keywords: B lymphocyte, centenarian, immunosenescence, longevity.

\section{INTRODUCTION}

Immunosenescence is considered a major contributory factor to the increased frequency of morbidity and mortality among elderly. It renders elderly increasingly susceptible to infectious diseases, leads to resurgence of latent infections, and also to infection by opportunistic organisms. These infections contribute significantly to morbidity in this age-group, and frequently lead to irreversible frailty and dependency. In addition, there is a decline in the protective effect of vaccination in the elderly [1-7]. Lifelong and chronic antigenic load seem to be the major driving force of immunosenescence, which impacts on human lifespan by reducing the number of virgin antigen-non experienced cells, and, simultaneously, filling the immunological space with expanded clones of memory and effector, antigen-experienced cells [7-9]. On the other hand, it has been demonstrated that centenarians escape the main diseases typical of aged and show well preserved immune functions. In fact immunosenescence is a complex process in which different immunological functions are remodeled and centenarians are an impressive demonstration of this phenomenon [10,11].

Prolongation of life expectancy has represented one of the humanity's greatest triumph in the 20th century. This unprecedented success is now one of society's greatest challenges. Improved child survival, reduced mortality rates, and decreasing fertility rates worldwide, is resulting in a rapid ageing of the world's population. This ageing is evident worldwide, and particularly evident in developing countries where the elderly population is predicted to quadruple over the next 25 years at which time it will represent over $25 \%$ of the total population. In particular, around the 60 's in all the industrialized countries the progressive decline of the mortality ( $-2 \%$ year) in individuals over- 80 years old has risen up of about twenty times the number of oldest old people. This has

*Address correspondence to this author at the Dipartimento di Biopatologia e Metodologie Biomediche, Università di Palermo, Corso Tukory, 211, 90134, Palermo, Italy; Tel: +39 0916555906; Fax: +39 0916555933;

E-mail: gcolonna@unipa.it increased the number of centenarians that nowadays are not more a curiosity, but in Europe are 1/8000 inhabitants [10,12,13].

Furthermore, centenarians are considered the best example of successful ageing $[10,11]$. To gain insight into mechanisms of immunosenescence and its clinical relevance, a possible model is represented by centenarians and/or their offspring. In fact, it has been demonstrated that the centenarian offspring, who are typically in their 70s and 80s, have a survival advantage when compared with age-matched controls whose parents died at an average life expectancy. Centenarian offspring, like their centenarian parent(s), have genetic and functional advantages associated with lower cardiovascular disease risk [14,15]. These findings support the hypothesis that centenarian offspring are predisposed to healthy aging and longer survival, making them a suitable target of ageing studies, because, unlikely of centenarians, they have an appropriate control group, i.e. common elderly.

Literature of immunosenescence has focused mainly on T cells, although B cell compartment is also affected in aged. Changes in B cell number and repertoire have been described and data in literature demonstrate that elderly frequently do not have protective antibody concentrations against recall antigens so suggesting the impairment of B cell branch [16,17]. The aim of this study was to compare some B cell parameters between healthy centenarian offspring and healthy age-matched controls to evaluate whether any difference exists in the naïve/memory B cell compartment that might explain the familiar increased lifespan expectancy of centenarian offspring. So, in the present preliminary report, we have studied B cell compartment in two classes of individuals, old people and centenarian offspring. B cell compartment was analyzed using anti-IgD and CD27 antibodies which characterize naïve B cells $\left(\operatorname{IgD}{ }^{+} \mathrm{CD} 27^{-}\right)$, memory unswitched B cells $\left(\operatorname{IgD}{ }^{+} \mathrm{CD} 27^{+}\right)$, memory switched $\mathrm{B}$ cells $\left(\operatorname{IgD} \mathrm{CD}^{-} 7^{+}\right)$and double negative $\mathrm{B}$ cells (DN) (IgD $\left.{ }^{-} \mathrm{CD}^{2} 7^{-}\right)$, i.e. exhausted memory cells $[18,19]$. In fact we have recently demonstrated an increase of late (exhausted) memory B cells in elderly [20] also accompanied by a decrease of serum IgM, so confirming the loss of naïve cells/products (i.e. antibodies) in the elderly [21]. Here we show that centenarian offspring have an 
increased amount of naïve B cells and IgM when compared to their controls, whereas we do not observe the increase of DN B cells shown in healthy elderly people.

\section{MATERIALS AND METHODS}

Twenty-nine Sicilian centenarian offspring (CO, age range 5983 , mean $73.4 \pm 7$ years), with almost one of their parents centenarian (>99 years), whose age had been confirmed from records at the city hall and/or church registries, were studied. A total of 25 age-matched Sicilian controls (A-M) (age range 60-85, mean $78.6 \pm 4.7$ years) were also included in the study. All subjects were in good health according to their clinical history and blood tests (complete blood cell count, erythrocyte sedimentation rate, glucose, urea nitrogen, creatinine, electrolytes, $\mathrm{C}$ reactive protein, liver function tests, iron, proteins). The study received approval from local ethic committee and all participants gave their informed consent.

Peripheral blood mononuclear cells (PBMCs) were isolated from heparinized venous blood by density gradient centrifugation on Ficoll-Lympholyte (Cedarlane Laboratories Limited, Ontario, Canada). PBMCs were adjusted to $1 \times 10^{6} / \mathrm{ml}$ in RPMI 1640 medium (Euroclone, Devon, UK) supplemented with 10\% heatinactivated fetal calf serum (Euroclone), $1 \%$ penicillin/streptomicin, $10 \mathrm{mM}$ HEPES, and $1 \mathrm{mM}$ L-glutamine.

In order to evaluate the lymphocytes subsets, total PBMCs were stained with different combinations of the following monoclonal antibodies: anti-CD3, anti-CD4, anti-CD8, anti-CD16, anti-CD19. All the antibodies were directly coupled either to fluorescein isothiocyanate (FITC), phycoerytrin (PE) or PE-Cy7 (Pharmingen, BD Bioscience, Mountain View, CA, USA). To analyze B cell subsets, PBMCs were stained with the following monoclonal antibodies combination: anti-CD19 $9_{\mathrm{FITC}}$, anti-IgD $\mathrm{PE}_{\mathrm{PE}}$ and anti-CD27 $7_{\mathrm{APC}}$ (Pharmingen).

All measurements were made with a FACSCalibur flow cytometer (Becton Dickinson, ${ }_{4}$ San Jose, CA, USA) with the same instrument setting. At least $10^{4}$ cells were analyzed using CellQuest Pro (Becton Dickinson, San Jose, CA, USA) software.

For IgG, IgA and IgM assay, the serum of all subjects was stored in aliquots at $-80^{\circ} \mathrm{C}$ until analysis and the immunoglobulin concentrations were determined by Integra 800 (Roche Diagnostics, Milan, Italy) according to manufacturer instructions.

Values, given as the mean $\pm \mathrm{SD}$, were compared using one-way analysis of variance (ANOVA). Differences were considered significant when a $\mathrm{p}$ value $<0.05$ was obtained by comparison between the different groups.

\section{RESULTS}

In Table 1 we report the percentage and absolute number of lymphocyte subpopulations evaluated in 29 centenarian offspring (age range $59-83$ years, mean age $73.4 \pm 7$ years) and 25 healthy age-matched controls (age range 60-85, mean $78.6 \pm 4.7$ ). As shown no significant differences have been observed between the lymphocyte values in the two groups studied.

So, concerning these lymphocyte subsets, centenarian offspring behave as the common elderly population.

Regarding naïve/memory B cell subsets, we analysed circulating $\mathrm{CD} 19^{+}$lymphocytes obtained by peripheral blood of centenarian offspring and their age-matched controls on the basis of the expression of $\operatorname{IgD}$ and $\mathrm{CD} 27$ into different functional subsets. These markers allow to divide blood B cells in four subsets, naïve B cells $\left(\operatorname{IgD}{ }^{+} \mathrm{CD}^{2} 7^{-}\right)$, memory unswitched $\mathrm{B}$ cells $\left(\operatorname{IgD}{ }^{+} \mathrm{CD} 27^{+}\right)$, memory switched $\mathrm{B}$ cells $\left(\mathrm{IgD}^{-} \mathrm{CD} 27^{+}\right)$and double negative $\mathrm{B}$ cells (DN) (IgD $\left.{ }^{-} \mathrm{CD}^{2} 7^{-}\right)$, i.e. exhausted memory cells [20] [Fig. (1) shows a characteristic plot].

In Table 2 we report the percentage and absolute number of these B lymphocyte subpopulations. As shown, the percentage and the absolute values of $\operatorname{IgD}^{+} \mathrm{CD} 27^{-}$naïve $\mathrm{B}$ cells are significantly increased in centenarian offspring when compared to age-matched controls. Instead, the percentages (but not the absolute values) of both $\operatorname{IgD}{ }^{+} \mathrm{CD} 27^{+}$memory unswitched $\mathrm{B}$ cells and double negative $\operatorname{IgD}{ }^{\top} \mathrm{CD} 27^{-} \mathrm{B}$ cells, i.e. exhausted memory cells, are significantly reduced in centenarian offspring. So, concerning these B cell subsets, centenarian offspring behave as the young population [20].

This observation is strengthened by serum immunoglobulin measurement. In fact, as displayed in Fig. (2), the concentration of IgM, a marker of the primary response, shows significant higher levels in centenarian offspring when compared to age-matched controls, whereas IgG and IgA levels are not significantly different between the two groups.

\section{DISCUSSION}

Ageing is a natural process that occurs in all cells, tissues, organs and organisms. It is modulated by both genetic and environmental factors. One of the most important characteristics of ageing is immunosenescence, that is the consequence of the continuous attrition caused by chronic antigenic load. The antigenic load results in the progressive generation of inflammatory responses involved in age-related diseases $[8,9,22]$. In the elderly many alterations of both innate and acquired immunity, have been described. The acquired compartment of immune system shows significant modifications in the elderly, in fact both $\mathrm{T}$ and $\mathrm{B}$

Table 1. Lymphocyte Subpopulations in 29 Centenarian Offspring (CO, Mean Age 73.4 Years, Age Range 59-83) and 25 AgeMatched Controls (A-M, Mean Age 78,6 Years, Age Range 60-85). Data are Expressed as Mean \pm SD of Absolute Numbers and Percentages. Significance has been Evaluated by ANOVA Test

\begin{tabular}{|c|c|c|c|c|c|c|}
\hline $\begin{array}{c}\text { Lymphocyte } \\
\text { subpopulations }\end{array}$ & $\begin{array}{c}\text { CO(29) } \\
\text { \% (MEAN } \pm \text { SD) }\end{array}$ & $\begin{array}{c}\text { A-M (25) } \\
\text { \% (MEAN } \pm \text { SD) }\end{array}$ & p & $\begin{array}{c}\text { CO (29) } \\
\text { Absolute Number }\end{array}$ & $\begin{array}{c}\text { A-M (25) } \\
\text { Absolute Number }\end{array}$ \\
\hline \hline CD3+ & $68.4 \pm 12.2$ & $64.9 \pm 10.8$ & 0.1 & $1483 \pm 494$ & $1352 \pm 360$ \\
\hline CD4+ & $46.2 \pm 11.4$ & $44.1 \pm 10.1$ & 0.2 & $952 \pm 421$ & $875 \pm 224$ & 0.3 \\
\hline CD8+ & $20.8 \pm 7.0$ & $18.8 \pm 7.2$ & 0.3 & $402 \pm 190$ & $152 \pm 107$ & 0.4 \\
\hline CD19+ & $7.7 \pm 3.8$ & $10.2 \pm 6.1$ & 0.3 & 0.3 & $277 \pm 184$ & 0.1 \\
\hline CD3-CD16+ & $12.1 \pm 7.3$ & $12.6 \pm 5.7$ & 0.3 & $267 \pm 149$ \\
\hline
\end{tabular}

$\mathrm{p}=$ values of CO vs. A-M. 

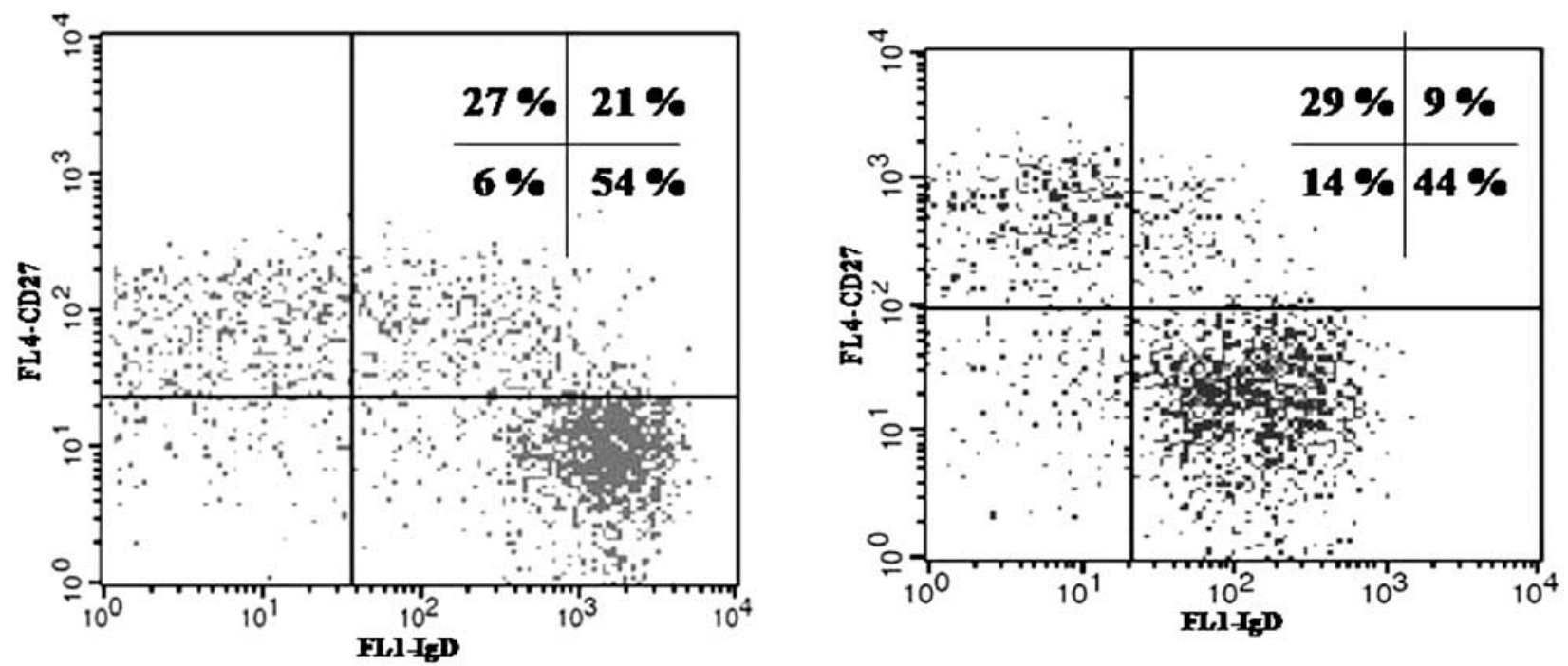

Fig. (1). Density Plot of memory/naïve B cells distribution. B subpopulations are identified by the expression of $\operatorname{IgD}$ and CD27 in centenarian offspring (A) and age-matched controls $(\mathbf{B})$. the analysis of Figure refers to cells gated as CD19+.

Table 2. B Cell Subsets of 29 CO Subjects, 25 A-M Controls as Analyzed According to the Expression of IgD and CD27. Data are Expressed as Mean \pm SD of Absolute Numbers and Percentage. Significance has been Evaluated by ANOVA Test

\begin{tabular}{|c|c|c|c|c|c|c|}
\hline $\begin{array}{l}\text { B Lymphocytes } \\
\text { subpopulations }\end{array}$ & $\begin{array}{c}\text { CO (29) } \\
\%(\mathrm{MEAN} \pm \mathrm{SD})\end{array}$ & $\begin{array}{c}\text { A-M (25) } \\
\%(\mathrm{MEAN} \pm \mathrm{SD})\end{array}$ & $\mathbf{p}$ & $\begin{array}{c}\text { CO (29) } \\
\text { Absolute Number }\end{array}$ & $\begin{array}{c}\text { A-M (25) } \\
\text { Absolute Number }\end{array}$ & $\mathbf{P}$ \\
\hline $\mathrm{IgD}^{+} \mathrm{CD} 27^{-}$ & $49.5 \pm 18.3$ & $36.1 \pm 17.8$ & 0.01 & $79.5 \pm 75.4$ & $43.0 \pm 41.0$ & 0.04 \\
\hline $\mathrm{IgD}^{+} \mathrm{CD} 27^{+}$ & $15.6 \pm 10.5$ & $24.1 \pm 14.7$ & 0.02 & $23.7 \pm 20.3$ & $28.3 \pm 32.2$ & 0.5 \\
\hline $\operatorname{IgD}{ }^{-} \mathrm{CD} 27^{+}$ & $26.0 \pm 15.4$ & $22.9 \pm 10.9$ & 0.4 & $37.2 \pm 27.3$ & $24.1 \pm 25.9$ & 0.1 \\
\hline
\end{tabular}

$\mathrm{p}=$ values of $\mathrm{CO}$ vs. A-M.
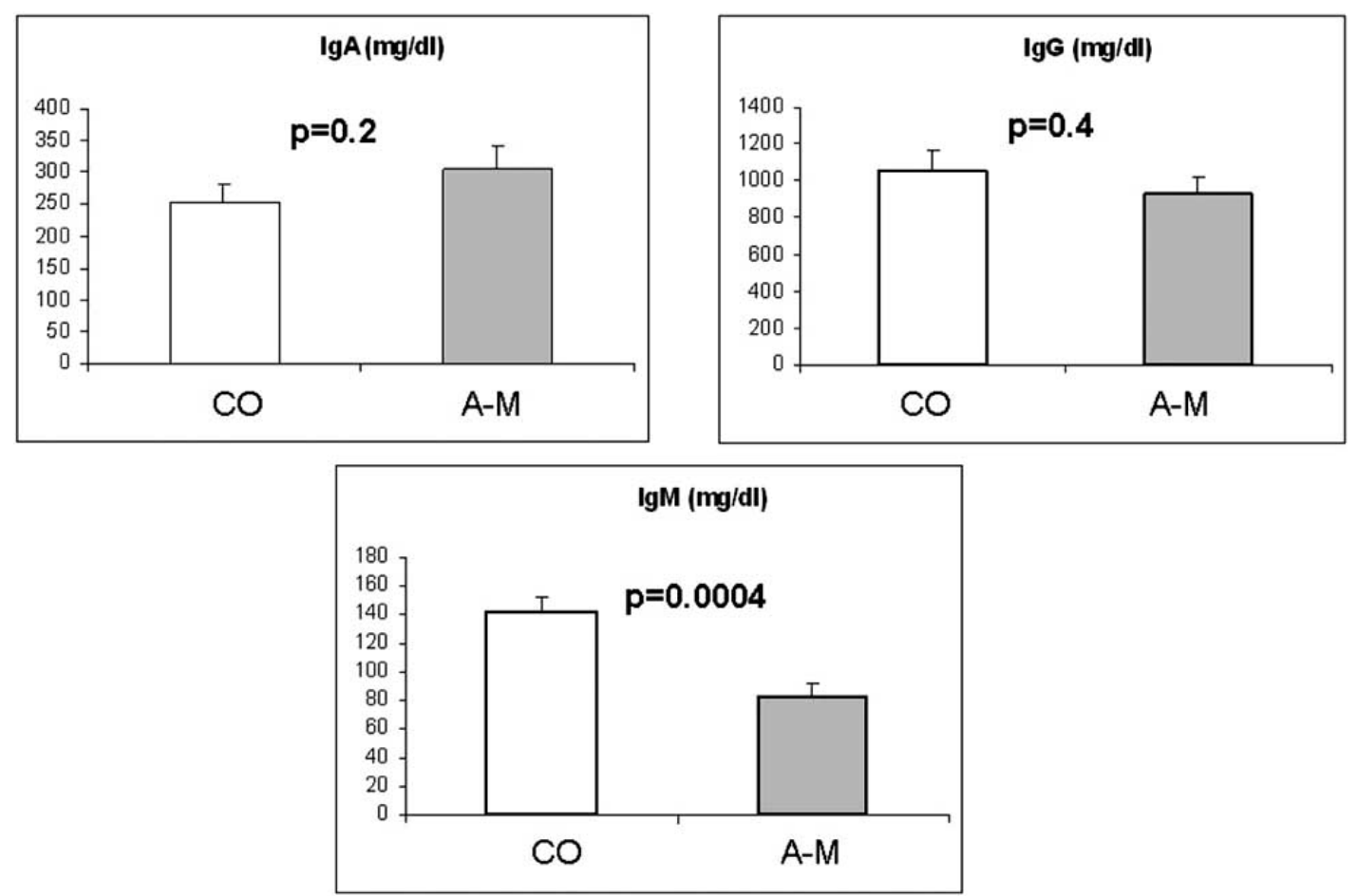

Fig. (2). Analysis of IgG, IgA and IgM serum concentrations in centenarian offspring (CO) and age-matched controls (A-M). 
[23] Derhovanessian E, Larbi A, Pawelec G. Biomarkers of human immunosenescence: impact of Cytomegalovirus infection. Curr Opin Immunol 2009; 21: 440-5

[24] Cancro MP, Hao Y, Scholz JL, Riley RL, Frasca D, Dunn-Walters DK. et al. B cells and aging: molecules and mechanisms. Trends Immunol 2009; 30: 313-8

[25] Sanz I, Wei C, Lee FE, Anolik J. Phenotypic and functional heterogeneity of human memory B cells. Semin Immunol 2008; 20: 6782.

[26] Anolik JA, Barnard J, Cappione A, Pugh-Bernard AE, Felgar RA, Looney RJ, et al. Rituximab improves peripheral B cell abnormalities in human systemic lupus erythematosus. Arthritis Rheumat 2004; 50: 3580-90.

[27] Pistoia V. Production of cytokines by human B cells in health and disease. Immunol Today 1997; 18: 343-50.
[28] Schultze JL, Michalak S, Lowne J, Wong A, Gilleece MH, Gribben $\mathrm{JG}$, et al. Human non-germinal center B cell interleukin (IL)-12 production is primarily regulated by $\mathrm{T}$ cell signals CD40 ligand, interferon gamma, and IL-10: role of B cells in the maintenance of T cell responses. J Exp Med 1999; 189: 1-12.

[29] Duddy ME, Alter A, Bar-Or A. Distinct profiles of human B cell effector cytokines. J Immunol 2004; 172: 3422-7.

[30] Pasare C, Medzhitob R. Control of B-cell responses by Toll-like receptors. Nature 2005; 438: 364-8.

[31] Vasto S, Scapagnini G, Bulati M, Candore G, Castiglia L, ColonnaRomano G, et al. Biomarkers Ageing Front Biosci 2009; in press

[32] Jirillo E, Candore G, Magrone T, Caruso C. A scientific approach to anti-ageing therapies: state of the art. Curr Pharm Des 2008; 14 : $2637-42$. 